\title{
O imaginário em (dis)curso: movências de sentidos sobre Biblioteca Pública
}

\author{
The imaginary in discourse: moving senses about public library
}

\begin{abstract}
Everton da Silva Camillo
Discente do curso de Biblioteconomia e Ciências da Informação e da Documentação da Faculdade de Filosofia, Ciências e Letras de Ribeirão Preto da Universidade de São Paulo - FFCLRP / USP.

E-mail: everton.camillo@usp.br
\end{abstract}

\begin{abstract}
Não basta saber ler que Eva viu a uva. É preciso saber qual a posição que Eva ocupa no seu contexto social, Quem trabalha para produzir a uva E quem lucra com esse trabalho.
\end{abstract}

Paulo Freire

\begin{abstract}
Resumo
O presente trabalho parte do desejo de colocar à mostra aspectos que cabem ao papel da biblioteca pública em uma sociedade dinâmica e requerente de constante informação, colocando em contraste o imaginário institucional da mesma projetado socialmente pelos usuários real e potencial tidos como passíveis dos seus serviços e recursos disponíveis na biblioteca, em contraste com a literatura das áreas a serem trabalhadas biblioteca e formações imaginárias -, assim como uma amostra do imaginário em torno dos conceitos criados por estudantes de Ciências da Informação e da Documentação e Biblioteconomia sobre a instituição já referida, que consolida na conclusão do trabalho.
\end{abstract}

Palavras-chave: Biblioteca Pública; Usuário; Imaginário

\begin{abstract}
This paper is part of a desire of exposing aspects that are concerned to the public libray role in a dynamic society that demands constant information in order to establish contrasts of the institucionalized imaginary from this public institution which is projected socially by the real and potencial users who are passable of its services and available resources, constrasting with the literature from its knwoledge areas to be brought into the development of this work - library and imaginary formations -, as well as a sampling of conceptual imaginary formations of students majoring in Information Science and Librarianship about this already mentioned institution that consolidate in the conclusion of this research.
\end{abstract}

Key words: Public Library; User; Imaginary 


\section{Considerações iniciais}

O estudante entra na biblioteca e dirige-se ao balcão de informações. Ele expõe o problema: quer saber o que existe ali sobre Villa-Lobos. Quem o atende aciona alguns botões, faz perguntas, manipula um teclado, fazendo surgir num visor uma série de indicações. Biografias do músico? Existem cinco no acervo. Quer consultálas? Vai levar para casa? Não vai precisar do catálogo de obras do compositor? Só para consulta, não pode ser levado para casa. Quer uma cópia? E discos? Obra pianística? Especifique. Consulte antes o catálogo de obras. Há, também, um documentário em vídeo, além das partituras, claro (MILANESI, 1985, p. 8-9).

De acordo com Milanesi (Ibid.), o trecho reproduzido acima retrata uma biblioteca que, de maneira infeliz, não representa a realidade sistêmica brasileira a qual o país vive em sua atualidade, porém é possível obtermos uma definição conceitual sobre o que viria a ser o termo biblioteca partindo da contribuição de Amora (2009, p. 91), quanto à significação apreendida em sua obra de referência que nos revela que a biblioteca é "sf. 1.Coleção de livros, dispostos de modo ordenado e em estantes, para estudo, leitura e consulta; 2. Recinto, edifício, sala ou móvel onde se encontram essas obras". Ainda na definição do termo, considerando-o em sua etimologia, Houaiss (2001, p. 190 apud MORIGI; SOUTO, 2005) destacam a gênese do mesmo, o qual se traduz por: "a palavra biblioteca tem sua origem do grego biblíon (livro) e teke (caixa, depósito), portanto um depósito de livros”, e de maneira coesa, retomando a sua concepção do que é a biblioteca, partindo da função dessa instituição, Carvalho (1991, p. 23) relata que ao papel da biblioteca "destacam seu caráter de difusor cultural, de democratizador do saber" [...]. O mesmo ainda complementa que "a biblioteca segundo essas análises seria um agente transformador da sociedade." (CARVALHO, 1991, p. 23). Entretanto, partindo das expectativas sociais, quanto à materialização dessa definição no âmbito social, é possível estabelecermos um consenso crítico de que o modelo de prestação de serviço bibliotecário presente no Brasil não garante a correta ação daquilo que lhe foi atribuído - atribuições essas que, ora, foram estabelecidas para servir à população largamente.

$\mathrm{Na}$ realidade, de acordo com as concepções de Milanesi (1985), existe uma real ausência de bibliotecas em muitos municípios brasileiros se considerarmos essa abordagem a partir dos aspectos básicos dessa determinada instituição, a considerar: infraestrutura, acervo, profissionais, acessibilidade e a exposição das obras existentes no acervo, uma vez que é necessário abordar antecipadamente, e de maneira meticulosa, o que tem recebido título de biblioteca nesse contexto social sem ao menos merecê-lo, considerando que uma biblioteca tem em sua função fim servir a um determinado público, isto é, “[...] quanto mais

\footnotetext{
${ }^{1}$ HOUAISS, A. Dicionário Houaiss da Língua Portuguesa. Rio de Janeiro: Objetiva, 2001.
} 
diversificado for esse público, mais diversificado será esse acervo" (MILANESI, 1985, p. 14) e, consequentemente, sua base local para o desenvolvimento das suas atividades fim obrigatoriamente deverá ser melhorada para prontamente receber o público, o qual é necessário saciar necessidades informacionais. Porém, o que se pode notar dessa contextualização da realidade biblioteconômica no Brasil é o fato de que a identidade da Biblioteca tem sido ofuscada. Não se sabe o que pode ser considerado biblioteca em dias atuais. Será um grande recinto, edifício ou até mesmo sala imponente onde o saber permeie digna e constantemente de maneira que justifique a sua função e existência? Ou, será prateleiras escondidas? Acervo abandonado? Pó acumulado? De fato, biblioteca tem sido um termo amplamente usado de maneira generosa, porém, naqueles lugares onde se anuncia a existência de uma, em parte dos casos, a biblioteca nada mais é que

[...] um armário com alguns livros escondidos em alguma sala da prefeitura. Só funciona para efeito de estatística. Segundo, como alguns rios nordestinos, as bibliotecas podem ser intermitentes: funcionam em alguns períodos. Outras, obedecendo ao ciclo da vida, nascem, crescem e morrem. (Ibid., p. 13).

Embora essa situação desconcertante seja justificada frequentemente às causas socioeconômicas do país, por meio de um subdesenvolvimento factível, outro viés pode ser tomado como ponto de partida para uma análise que venha nos levar a compreender um fato indissociável daquilo que pode se caracterizar como a solução para o aprimoramento educacional que, futuramente, justificará o empenho na construção, utilização, conservação e investimento às bibliotecas, como apontado por Milanesi (op. cit., p. 13), em que por meio da promoção dos intentos quanto à circulação informacional, desenvolvimento na área da pesquisa priorizando o ensino, frente a essa tomada de decisões quanto a investimentos, as bibliotecas merecidamente receberão o fomento que a elas cabe para que realizem exponencialmente o seu papel nessa conjuntura social.

É como se o Brasil vivesse vários tempos históricos: o século XX predominando nos
bolsões industriais espalhados pela vastidão do território com feições coloniais.
Existem bibliotecas e centros de documentação que acompanham e impulsionam o
desenvolvimento social nas áreas onde é mais florescente. Em contrapartida, as
bibliotecas das áreas mais subdesenvolvidas são um reflexo delas. Alegam os
administradores: se não há escolas, não há motivo para construir bibliotecas; se a
população não come, por que ler? O analfabeto morre em silêncio (Ibid., p. 13-14).

Ainda na visão de Milanesi (1985, p. 14), condensa-se o fato de que “[...] talvez, para os setores mais iluminados da administração brasileira, seja tácito que a educação, a pesquisa, o controle informativo, são peças fundamentais no processo de desenvolvimento" a ponto de deixar sobressair que, com a presença de uma desproporcional distribuição de renda, que 
contribui para um estado declarado de subdesenvolvimento em determinadas regiões do país, devemos considerar que os aspectos socioeducativos como o escolar, bibliotecário e de leitura tornam-se reflexos piorados de toda uma situação. E como forma de expor a relevância desse fator real, não é de hoje que se percebe o quão preocupante tem sido a relação das bibliotecas públicas no contexto social da atualidade quando se trata a respeito das suas ações e deveres, as quais pouco se destacam como estando em efetiva prática. Entretanto, independentemente das suas subexistências, conceitualmente, é importante apontar aspectos que se mesclam em meio a essa miscelânea conceitual, havendo a possibilidade de se instaurar uma fronteira entre aquilo presente no campo do conceitualmente criado - aspecto utópico, mediante a conjuntura atual - e do o que fervorosamente ocorre no plano do prático. E tratando do aspecto conceitual, diga-se que

\footnotetext{
A biblioteca pública é um espaço de inserção dos sujeitos ao exercício da cidadania, auxiliando-os no desenvolvimento da criticidade e da criatividade e proporcionando diversas trocas de experiências, por isso sua importância cultural e social para a sociedade (CASTRO, 2013, p. 9).
}

Para Suaiden (1995), através de uma abordagem histórica, é possível perceber que desde o período de décadas passadas a biblioteca pública tem sido olhada com indiferença pelos cidadãos, pois estes - em sua maior parte aqueles de pouca instrução - a classificam como um lugar onde são cultivados os valores das classes média e alta, onde o privilégio da cultura elitizada se sobressai e oculta o dos demais, quando a todos essa realidade deveria servir como propósito para buscar uma formação cidadã constante e apropriação cultural, exercendo assim, a biblioteca pública, sua atividade sociocultural expressivamente. Entretanto, para tais concepções, primeiramente devemos imaginar o que deveria ser uma biblioteca pública e qual a sua função na sociedade.

O papel das bibliotecas públicas é o de oferecer uma ampla diversificação de conteúdo aos membros da comunidade onde essas instituições se encontram inseridas, entretanto o que se pode observar como parte das suas realidades é uma decadência acentuada em seus acervos e baixa frequência de público em seus interiores, em busca da utilização dos seus serviços. Frente a isso é possível apontar o quão desinteressante esses locais têm se tornado. Nesse contexto, pretende-se introduzir o pensamento do quão importante essa instituição e suas abordagens são à sociedade, pois à Biblioteca Pública pertence o papel de garantir o acesso irrestrito à informação à população em prol da constante contribuição para saciedade de suas indagações e resgatando a proposta de Castro (2013, p. 16) é importante considerarmos que é 
[...] inegável a importância da Biblioteca Pública para a humanidade, como instrumento de custódia de sua própria história. Nesse sentido, a unidade de informação tem a função de salvaguardar a memória, quando armazena diferentes materiais bibliográficos em diversos suportes, garantindo acesso aos mesmos, por todas as pessoas que demonstrem interesse em consulta-los, uma vez que suas instalações pertencem ao público.

Mediante a prévia abordagem da importância da Biblioteca Pública frente à sociedade, propõe-se que um dos propósitos desse estudo é apresentar alguns pontos de reflexão acerca dos estereótipos criados socialmente. Estereótipos esses que "[...] podem refletir nossas expectativas e teorias mais amplas sobre como pensamos que um grupo deveria se comportar" (BROWN; TURNER, 2002, p. $68^{2}$ apud WALTER; BAPTISTA, 2007, p. 28) mediante discussões que envolvem as construções imaginárias baseadas em ideologias propostas pela Análise do Discurso de matriz francesa. Também, com relação a esse processo, refletir sobre a atuação desses estereótipos no imaginário dos usuários sobre a imagem, deveres e ações da organização biblioteca pública que, mediante a abordagem imediata do tema, em muitas das vezes, tem cunho negativo em esfera social - o imaginário de raízes negativas impede que os públicos em potencial e real, independentemente de credo, raça, idade, orientação sexual, nível intelectual e grau de instrução possam se integrar de forma participativa e realizadora na função sociocultural desse tipo de unidade de informação.

\title{
No âmago da Biblioteca Pública: sobre seus deveres e atuação social
}

\begin{abstract}
E começaram a surgir as primeiras perguntas que iam aos pontos fundamentais: Para que servem as bibliotecas? Para que serve a leitura? Para que serve a cultura que as bibliotecas públicas procuram difundir? $\mathrm{O}$ que fazem as bibliotecas públicas para solucionar problemas comuns, do cotidiano, de pessoas incultas que vivem às voltas com questões práticas e que nada têm a ver com o ideário lírico-sentimental e condoreiro de um século passado? (SUAIDEN, 1995, p. 8).
\end{abstract}

Sabe-se que em países discursivizados socialmente como "adiantados" existe uma calorosa discussão acerca do real papel de uma biblioteca pública que, em terras onde o desenvolvimento há muito já chegou, é uma temática de elevada importância.

Através de abordagens históricas estabelecidas é possível perceber que desde o período da década de 50 a biblioteca pública tem sido olhada com indiferença pelos cidadãos da própria comunidade a que elas legitimamente pertencem, pois esses têm um olhar que a

\footnotetext{
${ }^{2}$ BROWN, P. M.; TURNER, J. C. The role of theories in the formation os stereotype content. In: MCGARTY, C.; YZERBYT, V. Y; SPEARS, R. Stereotypes as explanations: the formation of meanigful beliefs about social groups. Cambridge: Cambridge University Press, 2002. p. 67-89.
} 
classifica como um local onde são cultivados os valores que fogem das suas realidades, como aqueles da classe média, assim como o privilégio da cultura da elite social.

Muitas são as concepções acerca do real papel da biblioteca pública no cenário da atualidade, inclusive discussões entre especialistas sobre tal assunto têm gerado inúmeras formulações que preenchem este pano de fundo sem quaisquer vestígios de maturidade cultural.

Quando pensamos nessa unidade de informação é possível concebermos que ela está intrinsecamente relacionada com a sociedade em geral, abarcando todos os cidadãos, independentemente da classe social ou grau de formação e considerando as diversas tipologias de biblioteca (híbrida, eletrônica, digital, virtual, especializada, universitária, infantil, particular), a pública é a que melhor se caracteriza como uma instituição social devido o seu caráter ligado fortemente ao eixo do social, onde o usuário igualmente se desenvolve no aspecto educacional, se autoeducando por meio de leituras e outras atividades de cunho cultural promovidas pela instituição (VIEIRA, 2014).

Também, como exemplo de responsabilidade institucional dessa organização indispensável à sociedade, soma-se a biblioteca popular que tem objetivos similares aos da biblioteca pública, no entanto, esta geralmente é desprovida de qualquer envolvimento cultural, formalidade e nível formal de conhecimento. Já a outra, dita pública, além de oferecer um contraste social, cultural e educacional, também desenvolve atividades locais de lazer que satisfaçam aqueles que pertencem à comunidade onde a mesma desempenha suas atividades.

No que diz respeito ao desenvolvimento econômico daqueles membros inseridos na comunidade onde a biblioteca está inserida, também é papel dela ser uma intermediadora de saberes e aspirações que possam contribuir para o desenvolvimento de tais pessoas, considerando as suas realidades profissionais. Isso se resume destacando um exemplo prático que venha abarcar a comunidade com aquilo que ela vive na prática profissional formal e informal do cotidiano: se na comunidade existe um grande número de pessoas que trabalham com costura, então seria interessante a biblioteca adequar parte do seu acervo a esse tema, com consequente desenvolvimento profissional e, sobretudo, além de organizar os exemplares, expor à comunidade tal feito alcançado, pois assim é criado um marketing para que usuários externos a essa transformação cheguem a requerer o serviço. E corroborando essa concepção mais inclusiva de caráter biblioteconômico, tanto sobre os aspectos laborais 
da comunidade, mas não apenas isso, Silva (2013) ressalta a extensão de tais conceitos inclusivos também àqueles pertencentes a outros estratos sociais, considerando em verdade que o papel das bibliotecas tem sido discutido como forma de compor uma teoria que abranja a efetiva integração de todas as pessoas na sociedade, independentemente de aspectos socioculturais e religiosos, promovendo uma crítica reflexão sobre o desempenho propício e esperado nessa conjuntura em prol do desenvolvimento de uma comunidade através de serviços correspondentes e apoio inclusivo.

Silva (2013) dialoga apontando que não apenas preza-se pela realização daquilo que é proposto no âmbito das discussões sobre responsabilidade das bibliotecas públicas, entretanto, além de prezado, é sabido que aos seus serviços o termo qualidade no gerenciamento da informação é um substantivo demandado às funções que elas detêm, mesmo que timidamente. Porém, a existência de requisitos bem singulares são primordiais ao alcance do que se propõe como uma nova abordagem inclusiva como proposta de atrativo para que membros da sociedade se identifiquem com as aspirações propostas nesses ambientes informacionais, atraindo assim, não apenas pelo caráter do desenvolvimento profissional, como já apontado, mas também pela crescente preocupação com grupos sociais que, em parte, não tem amplo alcance, pois são limitados frente a estruturas dos próprios locais, isto é, ambiente informacionais. "O caráter coletivo das bibliotecas e seu forte componente social, educativo e cultural, as convertem em instituições chave para conseguir que a integração de pessoas com deficiência e idosas seja uma realidade" (Ibid., p. 12).

Retomando àqueles requisitos essenciais, os definiremos como

[...] espaço e mobiliários apropriados para cadeirantes e pessoas com nanismo, pistas táteis, livros digitalizados e em braille para usuários cegos, recursos ópticos para pessoas com baixa visão, atendentes usuários de Libras para recepcionar surdos, espaços sem catracas, cadeiras adaptadas para pessoas obesas, grávidas e/ou idosas (SILVA, 2013, p. 12-13).

Costurando as menções, ainda colocando em foco uma discussão centrada no caráter social das bibliotecas, a UNESCO, em seu Manifesto, descreve a concepção totalizada dessa unidade de informação, considerando que em seu âmago a biblioteca de tipologia pública pode ser interpretada a partir de uma fé que a mesma pretende democratizar no âmbito da educação sistêmica, abarcando inúmeras faixas etárias que expressem um processo que, ao longo da vida, abram portas que possibilitem o conhecimento dos pontos descobertos pela humanidade pela via do saber e da cultura. 
O desenvolvimento das bibliotecas públicas no Brasil depende de inúmeras questões que são importantes à atividade vital dessas instituições. Sobremodo, é possível notar que em muitos municípios brasileiros uma biblioteca pública ainda é inexistente, e naqueles onde elas existem, muitas das vezes não são aprovadas por normas internacionais durante uma avaliação que visa qualificá-las como tal. E para corroborar com o fato, pergunta-se: onde tem estado a estrutura básica formadora da dinamicidade entre as bibliotecas? E os recursos financeiro e humano que visam o compromisso com a educação e cultura ordenados pelas autoridades? Frente a isso, é possível apontar que alguns dos fatores que dificultam o desenvolvimento de instituições bibliotecas no Brasil são

[...] falta de planejamento integrado e colaboração entre as bibliotecas; falta de conscientização dos governantes municipais quanto à importância que a biblioteca pública pode ter para o desenvolvimento sociocultural da comunidade; carência de recursos financeiros; carência de recursos humanos [...] pois apesar de existirem diversas escolas de biblioteconomia, os bibliotecários preferem permanecer nas grandes cidades, onde recebem um boa remuneração e gozam de melhores condições de especialização; a falta de boas livrarias nos municípios (SUAIDEN, 1995 , p. 31-32).

Retomando àquilo que pertence ao papel da biblioteca, ainda afirma (Ibid., p.45), que a formação de uma comunidade leitora é uma das ações idealizadas à biblioteca pública através da disposição e oferecimento de obras as quais a comunidade tem interesse em consultar, ler e se inteirar durante um relacionamento mais próximo com essa instituição "através de um acervo compatível com as necessidades da comunidade, por meio de pessoal qualificado e da comunicação direta com a comunidade”. Para que essa relação já idealizada não seja interrompida como forma de criar vínculos dentre os atuantes usuário e biblioteca, por que impor para que a comunidade leia uma determinada literatura, como a nacional, sendo que seu prazer de leitura está noutras obras? Afinal, a questão é desenvolver o hábito da leitura para que um espírito crítico venha ser composto e esse hábito vivificado, mas não impor bibliografias contrárias ao gosto do usuário criando um obstáculo nessa interação benéfica.

Como forma de avaliar as perspectivas imaginárias de alunos futuros bibliotecários sobre as ações e deveres de uma biblioteca pública assim como características que a ela seriam aplicáveis, mediante seus serviços e, sobretudo, mediante o discernimento dos entrevistados sobre o assunto, considerando que os mesmos são calouros na formação bibliotecária, um questionário foi aplicado a uma amostra de 24 pessoas, todos do primeiro ano do curso de Ciências da Informação e da Documentação e Biblioteconomia da Faculdade de Filosofia, Ciências e Letras de Ribeirão Preto, da Universidade de São Paulo, sendo 12 
homens e 12 mulheres compondo a pesquisa na íntegra, em que se pôde constatar que desse total, 20, isto é, $83,3 \%$ já haviam visitado uma biblioteca pública anteriormente, como aponta a Figura 1, entretanto, quando observado ambos os estratos - masculino e feminino concluímos que o serviço de empréstimo de livros é o que mais obtém sucesso dentro de uma instituição informacional como essa, a considerar que, entre os homens, essa atividade da biblioteca pública ocorre em $60 \%$ das vezes. Em segundo lugar, a realização de atividades escolares, com 30\% de ocorrência. Consulta de material no local correspondeu, entre aqueles do sexo masculino, a 10\% dessa observação (Figura 2). Já no caso das mulheres, a mesma opção de empréstimo de livros foi pontuada em $70 \%$ dos casos. Se tratando da realização de atividades escolares, o valor de $20 \%$ a representa e consulta de material no local representa $10 \%$ dos valores da amostra, como podem ser observados na Figura 3.

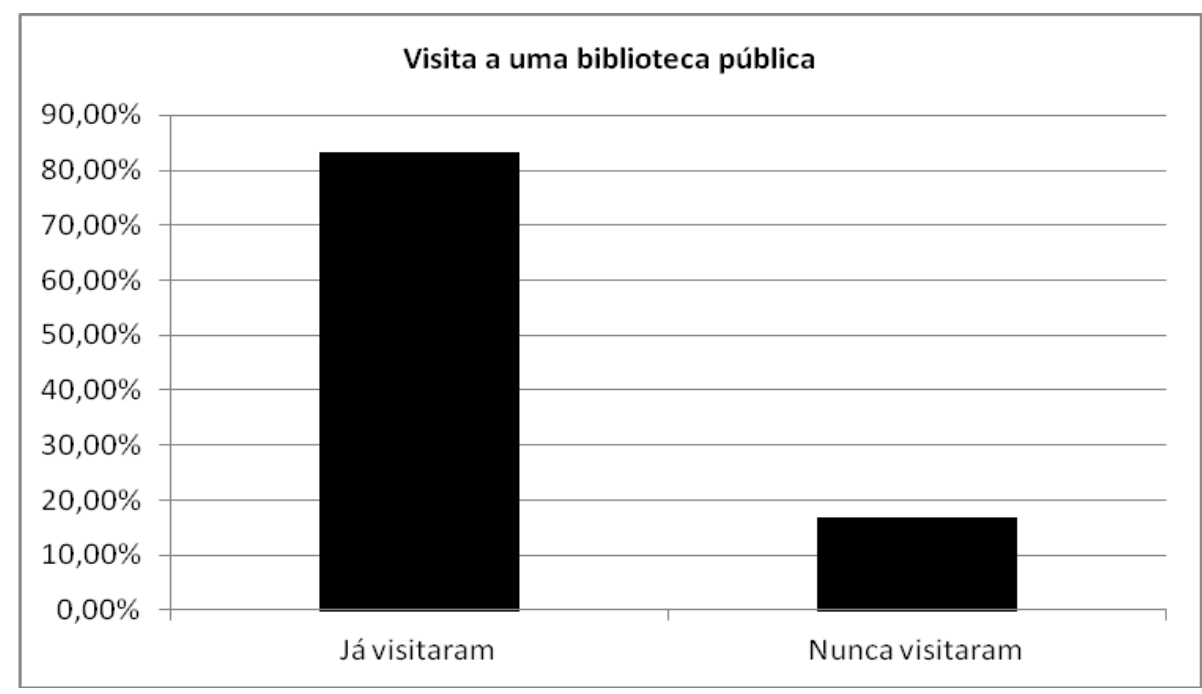

Figura 1 - Visita a uma biblioteca pública

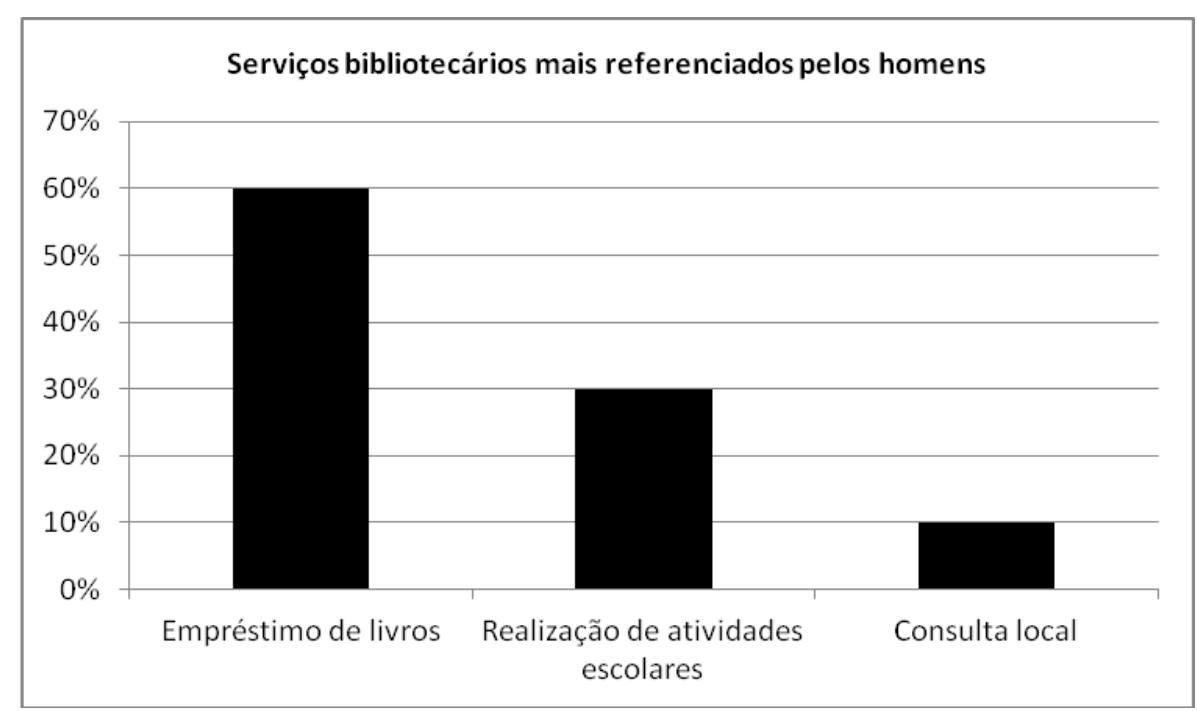

Figura 2 - Serviços bibliotecários mais referenciados pelos homens 


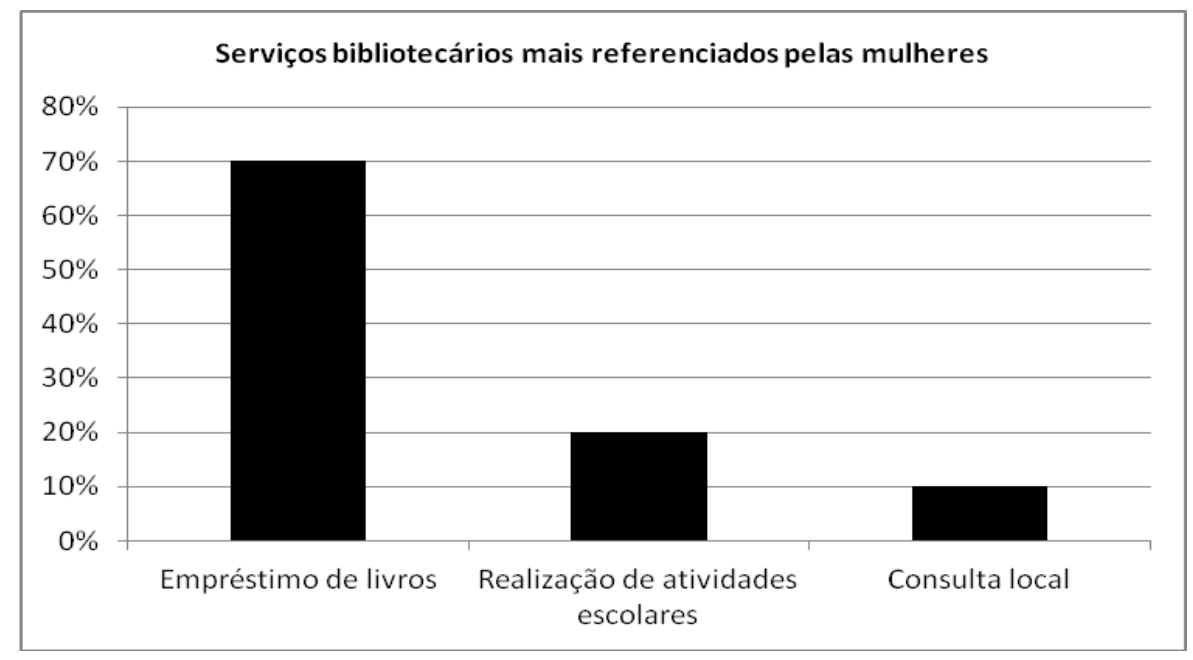

Figura 3 - Serviços bibliotecários mais referenciados pelas mulheres

É importante salientar que, na referida pesquisa realizada através da aplicação de questionário, foi possível a escolha de apenas uma alternativa dentre outras seis, com relação a que tipo de serviço o consulente questionado mais requeria à biblioteca nas vezes em que buscava pelos seus serviços, no entanto, por mais que se apresentem em diversos valores percentuais, todos os 24 questionados, isto é, $100 \%$ da amostra, utiliza a biblioteca pública apenas para as mesmas atividades, sempre voltadas à natureza escolar, empréstimo e consulta de material no local (como livros, mapas, manuais, atlas etc.). Tal dado constata a discussão proposta por Milanesi (1985, p. 54) sobre a ênfase no aspecto escolar presente nas prestações de serviço da biblioteca pública como uma função deslocada à originalmente proposta, considerando que um melhor ambiente, isto é, um ambiente mais propício às atividades direcionadas por professores, como pesquisas, passaram a caracterizar o ambiente das bibliotecas públicas, sempre um pouco melhores quanto a ambientação e disposição de material para receber alunos comparado ao escolar, fato esse traçado mediante uma historicidade em que "a partir de 1971 as bibliotecas públicas foram transformadas em bibliotecas escolares" devido às pesquisas que passaram a compor uma obrigatoriedade escolar que até a atualidade tem permitido que as bibliotecas pública assumam a já mencionada deslocada função.

Contrastando com aquilo que há na literatura, ao termos a afirmação de que, não só em favor de serviços bibliotecários, mas também dos de utilidade pública, "a biblioteca pública é um espaço de inserção dos sujeitos ao exercício da cidadania” (CASTRO, 2013, p. 9), o que corrobora com a observação feita na referida pesquisa em que percebemos que 
$100 \%$ da amostra se fideliza à biblioteca apenas com o intuito de utilizá-la como ambiente de desenvolvimento de atividades escolares e/ou como fonte de apropriação cultural, o que, em outra vertente, poderia ser considerado como um local também a ser utilizado como fonte de apropriação de informação utilitária em prol da continuidade de ações cidadãs à comunidade.

Os $16,7 \%$, isto é, 2 homens e 2 mulheres, que reclamaram nunca ter adentrado uma biblioteca pública, apontaram a falta de tempo, falta de conhecimento dos serviços disponíveis na biblioteca, horário de atendimento inconveniente e a falta de motivação como sendo os motivos por que não frequentam a referida instituição.

Em outra linha de pensamento, um ponto a ser trabalhado em instituições como as bibliotecas públicas, sustenta Suaiden (1995), é a informação utilitária, a qual foi estudada pela bibliotecária Ana Maria Polke. Este estudo revela os aspectos essenciais de informação à comunidade como saúde, emprego, legislação, educação, lazer e moradia, todos através da biblioteca atuando como intermediadora do desenvolvimento sociocultural, afinal, as necessidades de informação dos usuários são grandes o suficiente, e com relação aos nãousuários dos serviços públicos prestados por uma biblioteca pública estão as comunidades carentes, ditas como marginalizadas, que enfrentam não só a falta de bibliotecas públicas, mas também os problemas econômicos culturais e educacionais. É possível notar que quanto mais baixo é o nível socioeconômico do indivíduo, menor é a sua capacidade de obter informação e desenvolver sua atuação crítica no meio social. Todavia, um outro papel que se destaca à função da biblioteca pública, neste quesito, e que é pouco recordado é a integração das pessoas não-usuárias dos serviços devido o seu grau de letramento, considerando que, se a biblioteca é pública certamente não deve existir barreiras para selecionar possíveis usuário, assim, é direito de todos adentrarem ao local sem risco de discriminação ou restrição.

O nome mesmo "biblioteca pública" pressupõe uma biblioteca aberta a todas as
pessoas, sem nenhum tipo de discriminação. No entanto, o certo é que muitos grupos
sociais não utilizam a biblioteca, já que não empregam metodologias para integrar
em si as diversas pessoas que compõem a comunidade. Atender adequadamente a
este não-público é um objetivo fundamental da biblioteca pública (Ibid., p. 62).

Outra definição sobre o que, de fato, vem a ser uma concepção fundamental sobre a Biblioteca Pública, inserida no contexto sociocultural, pode ser encontrada na abordagem de Almeida Júnior (1997, p. $22^{3}$ apud ALMEIDA JÚNIOR, 2003, p. 67-68) quando o mesmo expõe que

\footnotetext{
${ }^{3}$ ALMEIDA JÚNIOR, O. F. Bibliotecas públicas e bibliotecas alternativas. Londrina: Ed. da UEL, 1997.
} 
O imaginário em (dis)curso: movências de sentidos sobre Biblioteca Pública

[...] biblioteca pública não pode ser entendida, simplificadamente, como oriunda dos reclamos das classes populares ou, inversamente, pelas benesses das classes detentoras do poder. [...] A biblioteca pública surge, não isoladamente, deslocada dos acontecimentos e da situação da sociedade [...]. A biblioteca pública deve ser reflexo e causa das transformações da sociedade; deve receber influências, interferir, ser início e fim das alterações sociais, numa sequência interminável. Sua origem esteve sustentada por esse quadro.

\section{Estereótipos e formações imaginárias: a formação de um conceito já-la}

Com o intuito de abordar aspectos sobre o modo como se dão as formações imaginárias, enquanto estereótipos e conceitos já-la, Orlandi (2003) ajuda-nos a formular a concepção de que desde o momento em que saímos do ventre materno e, consequentemente, se estendendo durante todo o nosso desenvolvimento, ideias e conhecimentos vão se acumulando a formar um verdadeiro complexo de saberes e vivências, pois começando a partir do momento em que das relações sociais tomamos parte, passamos a integrar a sincronia conduzida pelos discursos que já estão em processo, o que faz com nós possamos integrá-los de maneira totalizada. Entretanto, mediante os nossos contatos passados e experiências com relação a nossa infância, família, amigos, religião, educação, escola, cultura, viagens realizadas, profissão, emprego, filmes vistos, livros lidos, ideologias, nível econômico, história de vida etc. - toda uma bagagem sociocultural -, há um processo de cristalização em nossa existência com o passar do tempo.

\footnotetext{
Em nossa formação social, se pensamos por exemplo a Universidade, podemos explorar algumas $[\ldots]$ possibilidades: a imagem que o professor tem do que seja um aluno universitário, a imagem que se tem de um pesquisador, a imagem que o aluno (o professor, $\mathrm{o}$ funcionário) tem de um Reitor, a imagem que o aluno (o professor, $\mathrm{o}$ funcionário) tem de um dirigente de um diretório acadêmico, a imagem que o aluno (o professor, o funcionário) tem de uma dirigente de uma associação de professores universitários etc." (Ibid., p. 41).
}

A partir daí, passamos a reconhecer pessoas, objetos e fatos baseados nesse conjunto conceitual já solidificado em abordagem significativa e interpretativa que se localiza em um imaginário concebido em que Orlandi (op. cit., p. 10) aponta como sendo “de um lado, [...] na movência, na provisoriedade que os sujeitos e os sentidos se estabelecem, do outro, eles se estabilizam, se cristalizam, permanecem".

Etimologicamente considerada, a palavra estereótipo está localizada no grego, onde o termo stereos se traduz como sólido, no entanto, esses padrões estereotipados, como debatem 
Walter e Baptista (2008 ${ }^{4}$ apud CASTRO FILHO, 2013, p. 229) "costumam ser associados a conceitos negativos manifestados quando é emitido julgamento acerca de algum tema, de uma determinada pessoa, de um grupo ou mesmo relacionado às ações”.

[...] os estereótipos são conceitos, julgamento(s) ou um conjunto de visões sobre uma realidade, tema ou pessoa, estando influenciados por aspectos implícitos (subconsciente e simbólico) e explícitos (consciente), passíveis de interpretação. Sabemos que esse estereótipo apresenta-se enraizado na história, visto que os discursos e as imagens que ele inscreve nascem de relações sociais (Ibid., p. 233).

Evidentemente, tal significância do termo é um padrão criado de forma a se estabelecer concepções quanto a algo, alguém ou a um fato, isto é, sem a atuação constante e inconsciente dos estereótipos no cotidiano do homem, seria impossível criarmos uma relação de reconhecimento e identificação com a realidade da qual fazemos parte e onde os nossos feitos realizamos, o que também pode ser exemplificado, corriqueiramente, através da representação de uma situação recorrente em grandes centros urbanos, em que

\begin{abstract}
Se ouvimos, por exemplo, um barulho confuso e rangidos de ferro e lata que se torcem, fragor de vidros que se partem, diremos que houve uma colisão de carros, embora não estejamos presentes ao acontecimento. Isso porque já temos uma ideia prévia, e mais ou menos padronizada, do que seja um acidente de carro. (BLIKSTEIN, 2005, p. 54).
\end{abstract}

Em tessitura e dialogismo com a concepção de Blikstein (2005), mediante recorte acima citado, Orlandi (2003, p. 39) permite-nos entrelaçar outra abordagem acerca do tema, afinal, “[...] não há discurso que não se relacione com outros. Em outras palavras, os sentidos resultam de relações: um discurso aponta para outros que o sustentam”.

De acordo com a sua conceituação, tecendo sentidos, Orlandi (2003, p. 20) refere que “as palavras já chegam carregadas até nós de sentidos que não sabemos como se constituem e que, no entanto, significam em nós e para nós", pois a ação de interpretar automaticamente conduz os sentidos a filiações de sentidos já existentes, ocasionando em conduções quanto a formações ideológicas e estereotipadas.

Em debate anterior vimos como estereótipos fazem parte do nosso cotidiano a fim de nos ajudar a reconhecer e identificar a realidade humana sem a perda dos sentidos com consequente alienação e, juntamente a eles, encontram-se as imagens formuladas - quer sejam criadas pelas próprias instituições à sociedade ou até mesmo criadas no imaginário do homem em todos os âmbitos sociais - que "constituem as diferentes posições. E isto se faz de tal

\footnotetext{
${ }^{4}$ WALTER, M. T. M. T.; BAPTISTA, S. G. Formação Profissional do Bibliotecário. Encontros Bibli, Florianópolis, n. 25, 1 sem. 2008.
} 
modo que o que funciona no discurso não é o operário visto empiricamente, mas o operário enquanto posição discursiva produzida pelas formações imaginárias" (ORLANDI, 2003, p. 40-41).

Ao estereotipo também cabe o papel de apontar as percepções daqueles atuantes na esfera social, tematizando indivíduos, fatos e instituições, onde, no que aponta Pêcheux (1997, p. $157^{5}$ apud CARVALHO; ROMÃO; GALLI , 2013, p. 232), "todos os indivíduos recebem como evidente o sentido do que ouvem e dizem, leem ou escrevem (do que eles querem e do que se quer dizer), enquanto "sujeitos-falantes"”, que permite-nos compreender que o sujeito não é quem detém a criação dos seus dizeres, mas sim, mediante a discursividade apropriada através de discursos de outrem, aquele que se filia a uma teia ideológico-vocabular que permanece em constante tessitura.

Ao considerarmos a concepção de uma organização, a sua imagem pública está diretamente ligada àquilo que social e organizacionalmente a instituição está atribuída a fazer, como relatam Bernardino e Suaiden (2011, p. 25). Assim, a afirmativa dessa abordagem apontada se traduz claramente ao expormos que

[...] uma representação coletiva de um discurso imaginário, correspondente à leitura e à interpretação que a sociedade, ou cada um dos seus grupos ou estratos, têm e constroem de modo intencional ou espontâneo a respeito de uma determinada organização (CHAVES, 1996, p. $11^{6}$ apud Ibid., p. 25).

Apoiada pelas abordagens de Bernardino e Suaiden (2011), a imagem que a própria biblioteca sustenta e propaga de si, perante a sociedade, tem total relação com os valores que os membros que dela participam, compartilham. Valores esses que se consolidam em construção mediante fatos históricos e sociais. Entretanto, sabemos que a visão institucional da biblioteca não condiz com a imagem propagada pela sociedade sobre a mesma, assim como também não condiz com aquela formada sobre o profissional bibliotecário, em que, longinquamente, "as palavras "biblioteca" e "bibliotecário" são permeadas por estigmas e paradigmas, trazendo consequências, às vezes, negativas para a profissão" (CARVALHO; ROMÃO; GALLI, 2013, p. 239) tanto de atuais quanto de futuros profissionais da informação, pois

\footnotetext{
${ }^{5}$ PÊCHEUX, M. Semântica e discurso: um crítica à afirmação do óbvio. Campinas: Ed. da UNICAMP, 1997.

${ }^{6}$ CHAVES, Norberto. La imagen corporativa: teoria e metodologia de La identifi cación institucional. 4. ed. Barcelona: Gustavo Gili, 1996.
} 
[...] inferimos que o bibliotecário encontra-se historicamente relacionado ao ofício de guardião/zelador da biblioteca, responsável pela integridade e manutenção dos acervos, limpeza e organização física dos livros, com a autonomia para cobranças e impedimento de acesso às obras (DICKINSON, $2002^{7}$ apud Ibid., p. 233-234),

fato que continuamente reverbera através de discursos de outrem na hereditariedade social.

Desse modo, “[...] a imagem é um conceito construído na mente do público, a partir de um estímulo não necessariamente real [...]" (BERNARDINO; SUAIDEN, 2011, p. 28) e

Nesse sentido, o profissional tende a se distanciar do diálogo com o usuário, o que pode prejudicar o seu (re)conhecimento e, ainda, deflagrar a sua baixa autoestima, evidenciada pelo "grande desconforto que o sujeito profissional apresenta diante de sua própria imagem e da imagem socialmente construída e que prejudica a popularização da profissão [...] (VIEIRA, 2008, p. $112^{8}$ apud CARVALHO; ROMÃO; GALLI, op. cit., p .234).

Como apontam Carvalho, Romão e Galli (Ibid., p. 234) "sabemos que as possíveis condições de produção desses sentidos podem apontar para: [...] a ausência de bibliotecas nas instituições ou baixa assiduidade em tais unidades" assim como "[...] a falta de estímulo à leitura ou de atividades culturais que visem "fidelizar" o leitor", "[...] a presença de nãobibliotecários no mercado", que não só deixam de dialogar e investigar qualificadamente as necessidades informacionais do consulente em unidades de informação, ainda subdesenvolvidas, mas que também permitem com que

\begin{abstract}
Esse processo de formação da imagem da organização, no caso aqui, a biblioteca pública, reúne como elementos principais: a identidade da organização - os estímulos; a imagem - que corresponde ao conceito que o público tem da organização; e um trabalho corporativo - que é responsável pela diferença entre as percepções. Um interferindo no outro e se retroalimentando, em um processo contínuo (BERNARDINO; SUAIDEN, Ibid., p. 28).
\end{abstract}

Levando em conta a já mencionada pesquisa aplicada aos alunos do curso de Ciências da Informação e Documentação e Biblioteconomia do primeiro ano, questões sobre o imaginário institucional da biblioteca pública puderam ser apontadas através da análise do questionário aplicado, considerando, pontualmente, que o imaginário, segundo Orlandi (2003, p. 40) "[...] produz imagens dos sujeitos, assim como do objeto do discurso, dentro de uma conjuntura sócio-histórica" e tal evento é refletido no imaginário de ambos os estratos: masculino e feminino.

\footnotetext{
${ }^{7}$ DICKINSON, T. E. Looking at the male librarian stereotype. ARANT, W.; BENEFIEL, C. R. (Ed.). The images and roles of the librarian. New York: The Haworth Information Press, 2002. p. 97- 110.

${ }^{8}$ VIEIRA, I. M. Sentidos sobre o bibliotecário: a imagem do profissional no ciberespaço. 2008, 119f. Trabalho de Conclusão de Curso (Graduação em Ciências da Informação e da Documentação) - Universidade de São Paulo, Faculdade de Filosofia, Ciências e Letras de Ribeirão Preto, 2008.
} 
O imaginário em (dis)curso: movências de sentidos sobre Biblioteca Pública

Ao masculino, a Figura 4 ilustra em forma gráfica os percentuais existentes para cada atributo perguntado em questionário, com respostas alternando apenas entre sim ou não:

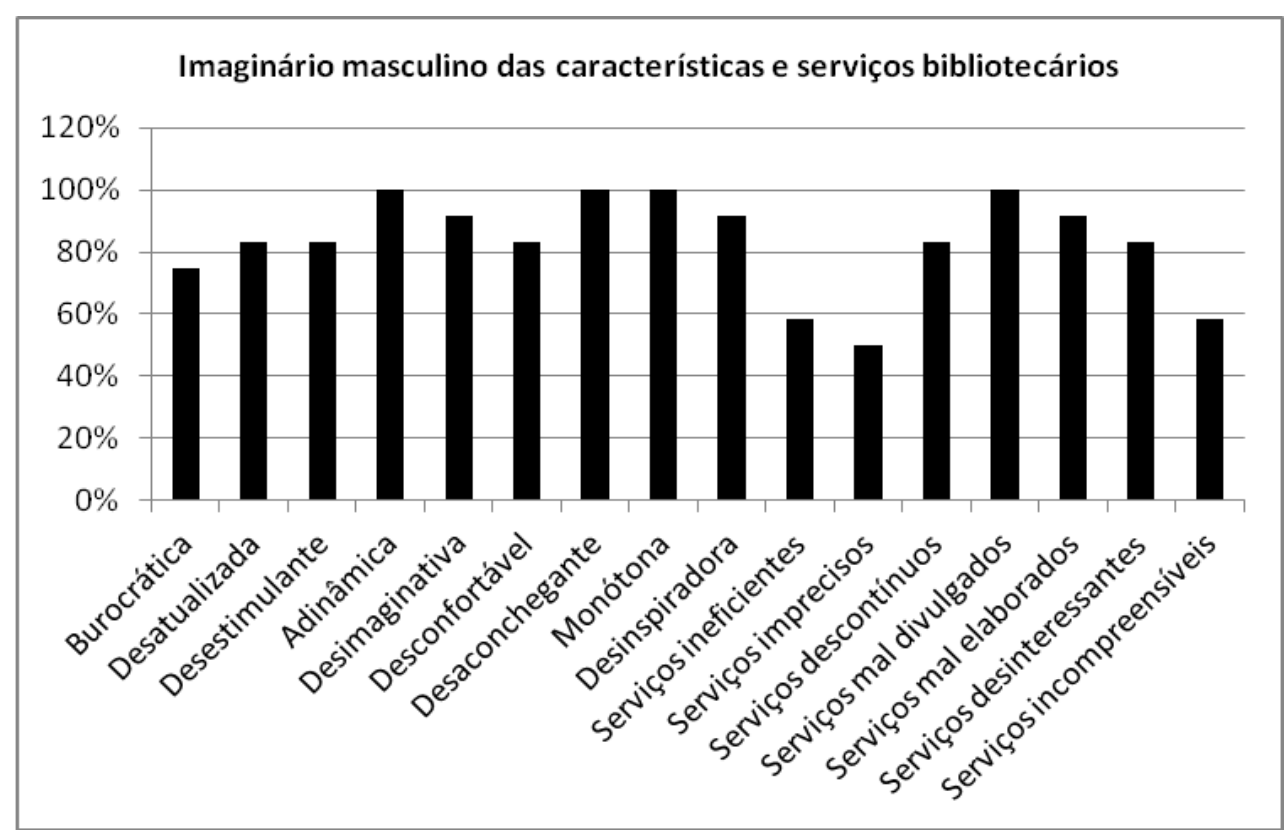

Figura 4 - Imaginário masculino das características e serviços bibliotecários

Ao estrato feminino, observando a mesma aplicação de técnica descrita acima, representado pela Figura 5, cabem os seguintes valores, também sobre toda a amostra:

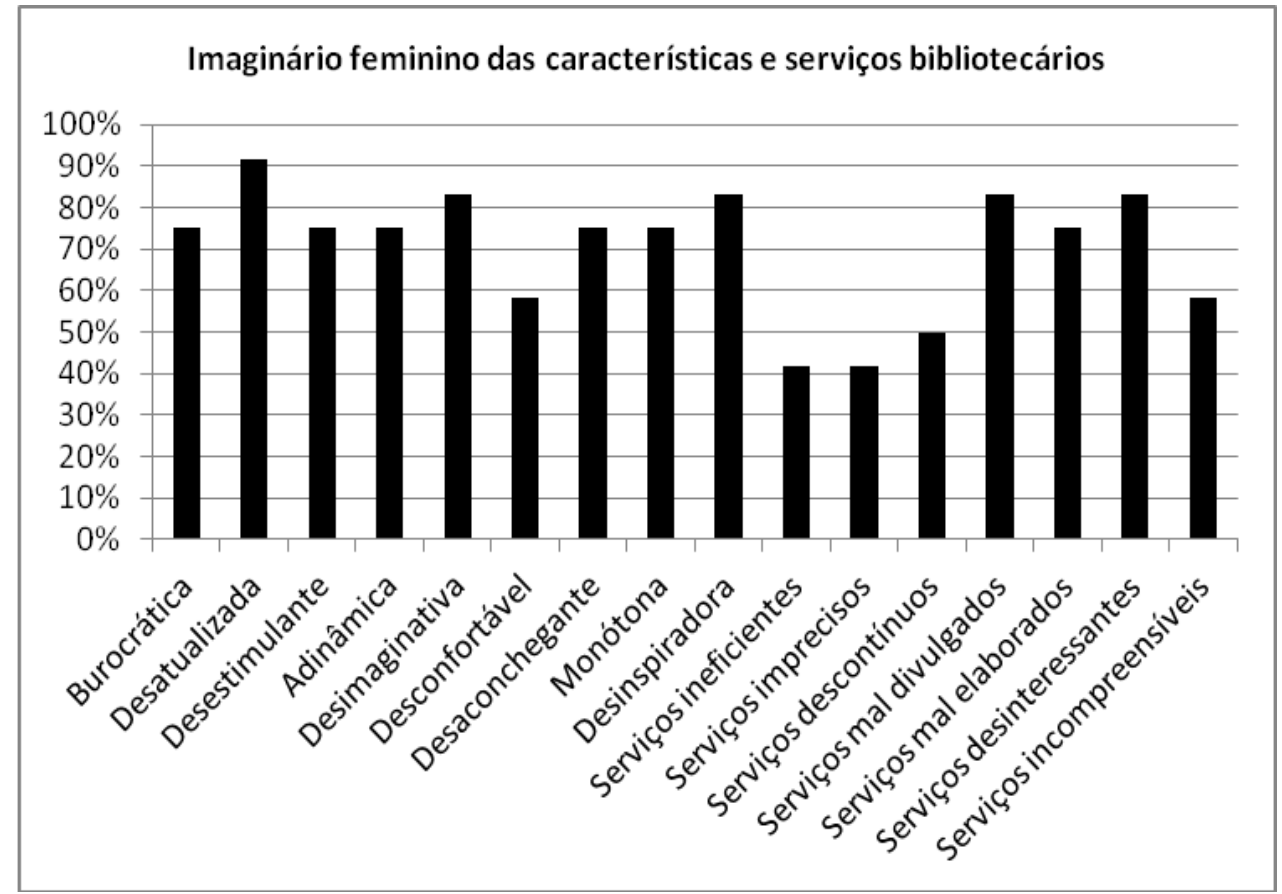

Figura 5 - Imaginário feminino das características e serviços bibliotecários 
Com relação aos resultados apresentados e interpretados, frente a colocações movidas no campo literário, apontamos que o funcionamento do discurso ocorre pela construção articulada entre os campos do imaginário e do real. A sua função não tem relação com a construção da representação da realidade, entretanto, garante que haja a permanência de uma já-dita representação discursiva. Assim, temos de considerar a abordagem de Orlandi (2003, p. 73) em que é dito que o criador de todo o discurso encontra-se na sua base discursiva: "o autor é o lugar onde se realiza esse projeto totalizante, o lugar em que se constrói a unidade do sujeito" discursivo.

\section{Considerações finais}

A literatura aponta o verdadeiro papel e responsabilidade social da instituição Biblioteca Pública no meio social promovendo o seu ideário de que a mesma deve ser local onde se promova a cidadania através de serviços envolventes, criativos, estimulantes, precisos e executáveis, e também o empréstimo de seus recursos, assim como seja capaz de promover digna apropriação cultural às pessoas da comunidade garantindo a participação de todos, independentemente dos fatores biopsicossocioculturais e religioso: a biblioteca pública deve sanar as necessidades informacionais da sociedade e permitir o acesso irrestrito a todos ao conhecimento com qualidade e equidade. Já os usuários, que criam as suas concepções e imagens baseadas em estereótipos dentro de um processo discursivo, resgatando nesse âmbito aquilo que propõe a memória discursiva - onde esses atuam como padronizações consequentes das idealizações no processo do desenvolvimento humano - recebem influências dos grupos onde estão inseridos, construindo suas imagens do que vem a ser as ações e deveres que podem ser caracterizados por uma livre espontaneidade ou, de modo intencional, conduzindo os discursos a respeito de uma determinada organização.

"Biblioteca, livro e velho se condensam, se integram e formam uma única entidade, indissociável, além de afastada dos interesses e necessidades da sociedade capitalista", como expressado no recorte de Almeida Júnior (1995, p. $4^{9}$ apud ALMEIDA JÚNIOR, 2003, p. 74), movendo conceitos imaginário-ideológicos cristalizados na sociedade que estão diretamente ligados ao imaginário dos usuários que compõem/comporiam a utilização dos serviços bibliotecários, visto que todo dizer é ideologicamente marcado, não havendo espaço para

\footnotetext{
${ }^{9}$ ALMEIDA JÚNIOR, O. F. Biblioteca pública: ambigüidade, conformismo e ação guerrilheira do bibliotecário. São Paulo: APB, 1995. 10 p.
} 
neutralidades no âmbito do já-la que é quando o político e o ideológico já realizaram (e ainda realizam) as suas influências.

Até mesmo apontando a "falta de conscientização dos governantes municipais quanto à importância que a biblioteca pública pode ter para o desenvolvimento sociocultural da comunidade", como refere Suaiden (1995, p. 31-32), existem discursos que corroboram com o mencionado recorte apontando para o que há cristalizado nos fundamentos sociais no que se refere ao profissional da informação discursivizado socialmente por meio do que Almeida Júnior (1995, p. $5^{9}$ apud ALMEIDA JÚNIOR, 2003, p. 74) propõe: “[...] bibliotecário é entendido como improdutivo, passivo, guardião do passado, ocioso, inútil, sem função social e, horror dos horrores, funcionário público".

O apontamento de Bernardino e Suaiden (2011, p. 32) contribui na tessitura presente de modo a considerar que a "[...] biblioteca pública, pelo conceito que atribuímos é maior que casos isolados e pontuais e não justifica uma adjetivação conceitual a um órgão público cujas atribuições são indissociáveis de seu caráter qualitativo", que em costura de ideias se alia ao que Sperry (1993, p. $170^{10}$ apud Ibid., p. 32) discursiviza agindo como forma de coletar dados preciosos para a montagem de uma modelo de biblioteca que conte com a participação da comunidade, mediante o seu imaginário e expectativas em que

Se fosse dado ao povo o direito de opinar sobre as bibliotecas públicas, constatar-seia que ele tem uma teoria sobre a questão, um contra-discurso constituído, uma verdade, que poderia notear bibliotecários e poder público na busca dos recursos estratégicos que lhe faltam.

De um lado podemos notar como o discurso institucionalizado da Biblioteca Pública permeia nas relações sociais a classificando como “[...] uma instituição democrática e depositária da história local, célula viva e única" como apontam Bernardino e Suaiden (Ibid., p. 28), o que, na realidade, dialoga em contrariedade prática com aquilo que temos visto corriqueiramente como prateleiras escondidas atrás de mesas de prefeitura sendo denominadas de biblioteca: a grande guardiã do saber - da comunidade. Ainda resgatando as contribuições por meio da defesa dos autores acima citados (Ibid., p. 30) "notamos que o entusiasmo do discurso se perde ante a realidade da qualidade dos serviços, que reflete uma desigualdade entre o discurso e a prática”, o que permite apontar que ainda há um abismo entre o fato idealizado e o produto apresentado, mesmo que diante dos esforços para mudar

\footnotetext{
${ }^{10}$ SPERRY, S. A verdade oculta na população sobre a biblioteca pública: soluções para revisar seu papel. Rev. Escola de Biblioteconomia da UFMG, Belo Horizonte, v. 22, n. 2, p. 169-180, 1993. Disponível em: <http:// portaldeperiodicos.eci.ufmg.br/reb/>. Acesso em: 21 jan. 2011.
} 
essa realidade ainda latente no Brasil. Entretanto, estima-se que outros trabalhos possam corroborar para o levantamento de outros fenômenos sociais, abordagens sobre o tema por outras perspectivas e discussões movidas no campo da literatura no âmbito do que é discutido acerca do imaginário e suas formações, estereótipos e cristalizações, bibliotecas enquanto deveres e serviços na sociedade e usuários reais e potenciais requerentes de constante informação.

\section{Referências}

ALMEIDA JUNIOR, O. F. Biblioteca pública: avaliação de serviços. Londrina: Eduel, 2003.

AMORA, A. S. Minidicionário Soares Amora da língua portuguesa. 19. ed. São Paulo: Saraiva, 2009.

BERNARDINO, M. C. R.; SUAIDEN, E. J. Concepção de imagem pública das bibliotecas pólos do estado do Ceará. Informação \& Sociedade, João Pessoa, v. 21, n. 2, p. 25-34, maio/ago. 2011. Disponível em:

<http://www.ies.ufpb.br/ojs/index.php/ies/article/view/9824>. Acesso em: 29 set. 2014.

BLIKSTEIN, I. Estrutura e funcionamento da comunicação. In: comunicação escrita. 21. ed. São Paulo: Ática, 2005. Técnicas de

CARVALHO, L. M. Biblioteca: instituição preservadora da cultura dominante?. Informação \& Sociedade, João Pessoa, v. 1, n. 1, p. 23-29, jan./dez. 1991. Disponível em: <http://www.ies.ufpb.br/ojs/index.php/ies/article/view/20>. Acesso em: 29 set. 2014.

CASTRO, P. A. Ação cultural e social na Biblioteca Olavo Bilac. 2013. Monografia (Trabalho de Conclusão de Curso de Ciências da Informação e da Documentação) Faculdade de Filosofia, Ciências e Letras de Ribeirão Preto, Universidade de São Paulo, Ribeirão Preto, 2013.

CARVALHO, M. G. M. D. A.; ROMÃO, L. M. S.; GALLI, F. C. S. O efeito imaginário em Curso: discursividade sobre/do bibliotecário. In: CASTRO FILHO, C. M. Olhares sobre o profissional da informação. São Paulo: Todas as Musas, 2013.

MILANESI, L. O que é biblioteca. 3. ed. São Paulo: Brasiliense, 1985.

MORIGI, V. J.; SOUTO, L. R. Entre o passado e o presente: as visões de biblioteca no mundo contemporâneo. ACB, Florianópolis, v.10, n. 2, p.189-206, jan./dez., 2005. Disponível em: 〈http://www.brapci.inf.br/_repositorio/2010/06/pdf_99864bb17b_0011138.pdf>. Acesso em: 20 ago. 2014.

ORLANDI, E. P. Análise de discurso: princípios e procedimentos. 5. ed. Campinas: Pontes, 2003. 
SILVA, C. C. O. Biblioteca inclusiva. 2013. 52f. Monografia (Trabalho de Conclusão de Curso de Biblioteconomia) Universidade Federal do Ceará, Juazeiro do Norte, 2013.

Disponível em: <http://www.todosnos.unicamp.br:8080/lab/links-uteis/acessibilidade-einclusao/textos/Biblioteca\%20Inclusiva\%20Carlos\%200liveira.pdf >. Acesso em: 20 out. 2014.

SUAIDEN, E. Biblioteca pública e informação à comunidade. São Paulo: Global, 1995.

VIEIRA, R. M. Introdução à teoria geral da biblioteconomia. Rio de Janeiro: Interciência, 2014.

WALTER, M. T. M. T.; BAPTISTA, S. G. A força dos estereótipos na construção da imagem profissional dos bibliotecários. Informação \& Sociedade, João Pessoa, v. 17, n. 3, p. 27-38, set./dez. 2007. Disponível em: 〈http://www.ies.ufpb.br/ojs/index.php/ies/article/view/962>. Acesso em: 20 out. 2014. 